Images in clinical medicine. Papillomatosis cutis lymphostatica

Kasper, Romano Silvio ; Nobbe, Stephan

DOI: https://doi.org/10.1056/NEJMicm1307463

Posted at the Zurich Open Repository and Archive, University of Zurich ZORA URL: https://doi.org/10.5167/uzh-92770

Journal Article

Originally published at:

Kasper, Romano Silvio; Nobbe, Stephan (2014). Images in clinical medicine. Papillomatosis cutis lymphostatica. New England Journal of Medicine, 370(1):69.

DOI: https://doi.org/10.1056/NEJMicm1307463 
IMAGES IN CLINICAL MEDICINE

Lindsey R. Baden, M.D., Editor

\section{Papillomatosis Cutis Lymphostatica}
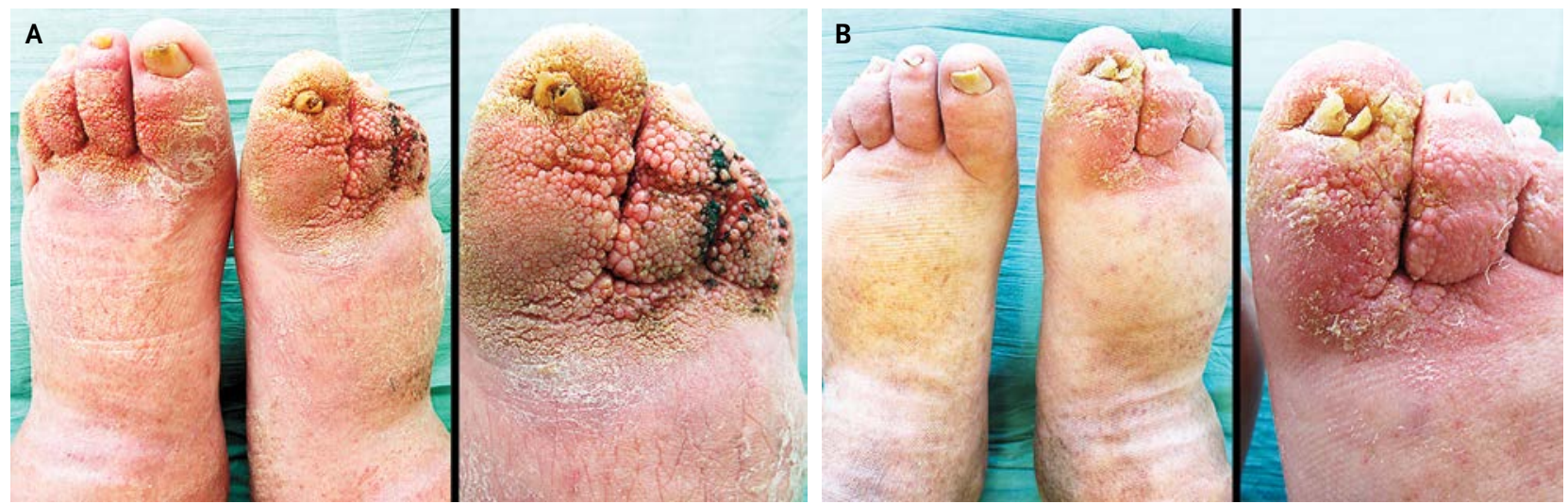

\section{$\Lambda$}

N 88-YEAR-OLD MAN PRESENTED WITH A 7-YEAR HISTORY OF ASYMPTOMATIC, enlarging papules on his feet and toes. He had a 30-year history of chronic venous insufficiency and chronic leg edema. Skin examination showed multiple skin-colored, confluent, partly hyperkeratotic, verrucous papules on both forefeet, as well as extensive pitting edema of the feet and legs (Panel A). The patient's history and clinical findings were consistent with papillomatosis cutis lymphostatica. This condition is a rare manifestation of primary (inherited) lymphedema or, more often, secondary lymphedema that can result from any disease or condition associated with damage to the lymphatic vessels, including chronic venous insufficiency. Skin infections may result from breaks in the skin caused by papillomatosis cutis lymphostatica. Options for effective treatment of papillomatosis cutis lymphostatica are limited; compression therapy is important to prevent further progression. This patient had no evidence of secondary skin infections. He was treated with compression bandages and topical 5\% salicylic acid ointment, and some improvement was noted at follow-up 3 months later (Panel B).
Romano Silvio Kasper, M.D. Stephan Nobbe, M.D.

University Hospital Zurich

Zurich, Switzerland

stephan.nobbe@usz.ch

DOI: 10.1056/NEJMicm1307463

Copyright @ 2014 Massachusetts Medical Society. 